\title{
Blade Vibration on Centrifugal Compressors - Fundamental Considerations and Initial Measurements
}

\author{
U. Haupt, K. Bammert, M. Rautenberg \\ Institute for Turbomachinery, University of Hannover, West Germany
}

\begin{abstract}
Blade vibration has to be considered in the design of high pressure ratio / high mass flow centrifugal compressors with increasing rotational speed values due to the reduced blade thickness. Results of a theoretical and experimental investigation concerning this problem are described. FE calculations of the stress distribution on the blade for the lower natural frequencies and various vibration tests at rest were carried out to investigate resonance and damping effects. This preparatory work was aimed at determining blade vibration behavior and acquiring fundamental experience for measurements on compressors in operation.

Results of blade vibration measurements on compressors with a vaneless diffuser carried out with semiconductor strain gages and an 8-channel telemetry system are presented for constant rotational speed and for constant throttle valve position, and indicate considerable blade excitation during stall effects. Simultaneous flow measurements complete the investigation to determine the causes of blade vibration. For example, investigations were made of the extent of blade resonance excitation due to non-uniformity of the flow downstream of the impeller or due to flow disturbances caused by carrier blades for bearings in the compressor inlet and simulated by spoilers.
\end{abstract}

\section{Introduction}

In the design of modern centrifugal compressors used in many applications such as turbochargers, higher pressure ratio and mass flow can be obtained by increasing the rotational speed. This can be achieved by the choice of better material or by reducing the blade thickness. This can lead to dangerous blade vibration, which has turned out to be a serious problem causing numerous defects during operation of compressors in the past. Accordingly, the vibratory behavior of compressor blades with attention to stress and excitation forces have to be considered in the stress design.

A great amount of research work has been carried out with respect to blade vibration and excitation effects with axial blades, especially for the prediction of blade frequencies, blade modes, flutter ranges and resonance effects. In radial compressors, not only the blade shape is very different from axial blades, but the excitation mechanism too is different from conditions on axial machines. For example, resonance effects on centrifugal compressors are mainly due to the non-uniformity of the flow downstream of the impeller. This is not known as a dominant excitation effect on axial compressors. Since little experience exists on blade vibration on centrifugal compressors, especially with respect to the properties and the intensities of the excitation forces occurring in the operating compressor, a broad research program on this subject has been implemented by the Institute for Turbomachinery in Hannover.

Whilst blade frequencies and modes of even complicated radial blade geometries can be calculated nowadays using the FE method, no theoretical method will give a prediction of the intensity of the excitation forces in the operating compressor. This was the reason to place special emphasis on experimental investigation of the flow behavior via parallel measurements. Both blade vibration and flow measurements will give information about the mechanism of blade excitation which might be useful for engineers carrying out the stress design of centrifugal impellers.

The following four excitation phenomena derived from axial compressor blade vibration research were considered to be important for the main theme of the program for this investigation:

- Blade vibration excitation due to aerodynamic non-uniformity of the flow in the inlet or exit range of the compressor. Resonance occurs between the blade frequencies and the engine orders.

- Self-excited blade vibrations due to operating the 
machine in the flutter regions of the compressor map.

- Blade excitation due to the cells of rotating stall.

- Blade excitation due to compressor surge.

It was the aim of this investigation to be able to evaluate these excitation phenomena with respect to the dangers of blade vibration and its material stress values.

This paper - and the following documented in $/ 1 /$ - discuss results of various previous papers of the authors indicated in the relevant references. They also include numerous new and current results. This paper deals mainly with preparatory theoretical and experimental activities and initial results from blade vibration measurements on operating compressors to investigate the influence of the non-uniformity of the flow down and upstream of the impeller. In /1/ results of measurements are presented which relate to the excitation of blade vibration due to different types of diffuser vanes, due to rotating stall cells and during compressor surge. Since dangerous vibrations of the whole impeller could be detected in the experiments on operating compressors, FE calculations were used to investigate the vibratory behavior of a $90^{\circ}$ sector of the impeller . Results of optical measurements using holographic interferometry in rotational motion yielded information on the mode shapes of the different blades of a rotating impeller.

First aspects of this investigation deal with experience from research on axial compressors; the choice of the measuring method and calibration and transmission problems are documented in $/ 2 /$ and $/ 3 /$. The test facilities for this investigation are described in $/ 4 /$. Figure 1 shows the radial impeller used for the blade vibration measurements. The characteristically thin impeller blades of about $1 \mathrm{~mm}$ at the blade inlet and $4 \mathrm{~mm}$ at the outlet are particularly suitable for this investigation. The impeller has a diameter of $d=$ $400 \mathrm{~mm}$ and 28 radial-ended blades with every second blade cut back at the impeller inlet.

Different measurement techniques for this investigation were considered in $/ 3 /$. Semiconductor strain gages with their high sensitivity factor were chosen to obtain information about blade vibration stresses. A multichannel telemetry system was selected for the signal transmission.

\section{Computation of Static Stress}

A considerable amount of theoretical and exper-

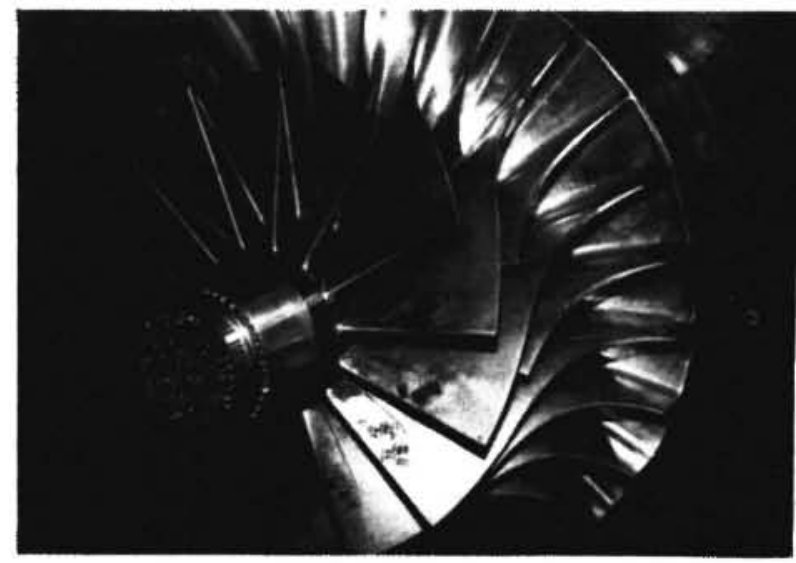

Fig. 1: View of the impeller used for the blade vibration measurements.

imental preparatory work was necessary before the beginning of the measurements. At first, the strain due to the centrifugal force had to be calculated by means of the FE (Finite Element) method. This was necessary because of the difficulty of measuring static stress with a superposed dynamic component with sufficient accuracy. With this calculation, mentioned in $/ 5 /$ and $/ 6 /$, the measuring problem was reduced to the vibrational part of the stress. Figure 2 shows the segment of the impeller used for the computation, the element distribution and the results for a rotational speed of $\mathrm{n}=20000 \mathrm{rpm}$ and for a measured temperature distribution. Several blade stress maxima occur along the hub; the maximum values were approximately $\sigma \approx 80 \mathrm{~N} / \mathrm{mm}^{2}$; the stress in the impeller reaches a maximum near the shaft. Similar calculations are described by Fister/Heiderich $/ 7 /$.

Evaluations of measurements involving steady aerodynamic loads were also made. The stresses involved turned out to be not very important compared with the stresses due to centrifugal forces.

\section{Computation of Blade Modes and Dynamic Stress}

Much work had to be carried out to choose the best attachment points on the blade for the strain gages. For this purpose, a detailed knowledge not only of the strain distribution during the vibrational motion, but also of the principal stress directions was essential. First of all, FE calculations were used to compute the natural frequencies and the mode shapes for the radial blade. Results for the first three modes are presented in $/ 5 /$ and $/ 8 /$, and show nodal lines 

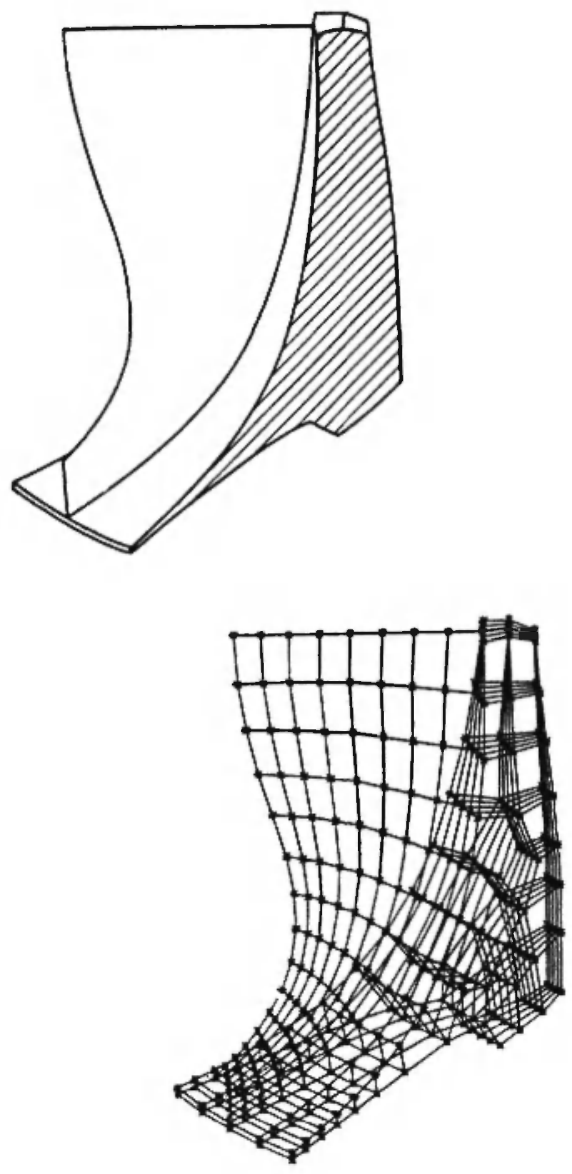

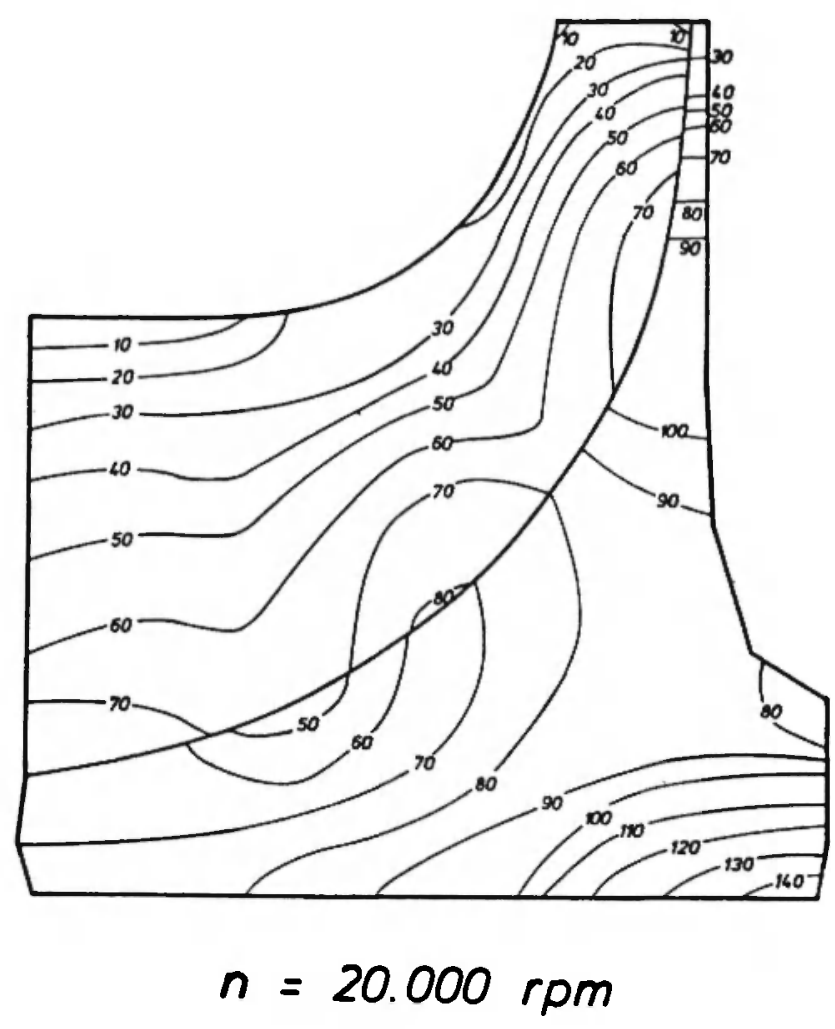

Fig. 2: Computed equivalent stress in the test impeller due to centrifugal force and temperature, section of the impeller used for the computation and element distribution for the FE computations. $\sigma_{V}=$ equivalent stress in $\mathrm{N} / \mathrm{mm}^{2}$

representing points of no displacement in the vibrational motion for the second and third mode. As can be seen in the results of this computation for the VI-X mode (Figure 3), vibrations of the blade outlet zone are mainly obtained for higher modes while strong displacements in the vibrational motion can be observed for the low blade mode numbers.

Information on the relative displacements of the nodal points of the blade element distribution was used to calculate absolute strain values and the principal strain directions during vibration in the different modes for a displacement of the inlet tip of $1 \mathrm{~mm}$. Results of the computation are shown in Figure 4 for the first three modes. In all cases, maximum values of principal strain were obtained in the inlet zone of the blade. The principal strain directions were also calculated; the results are described in $15 /$. This information about the stress properties during vibration of the radial blade and additional results of vibration tests at rest was used to determine the location and direction of maximum strain for the I and II modes. The strain gages were attached at the points of maximum strain and aligned with the principal strain direction. The latter were expected to predominate during operation of the compressor.

\section{Vibration Tests at Rest}

Various vibration tests were carried out to confirm the results obtained from FE calculations and to get additional information on the interactions of the vibrating blades of an impeller.

Reference /5/ describes a vibration test where one blade of an impeller at rest was excited to vibration followed by measurement of the stress amplitudes with 37 strain gage rosettes. Whereas /5/ presents results for vibration of the blade in the first mode, those for the second mode are shown in Figure 5. The arrows signify the amount of principal strain at that 

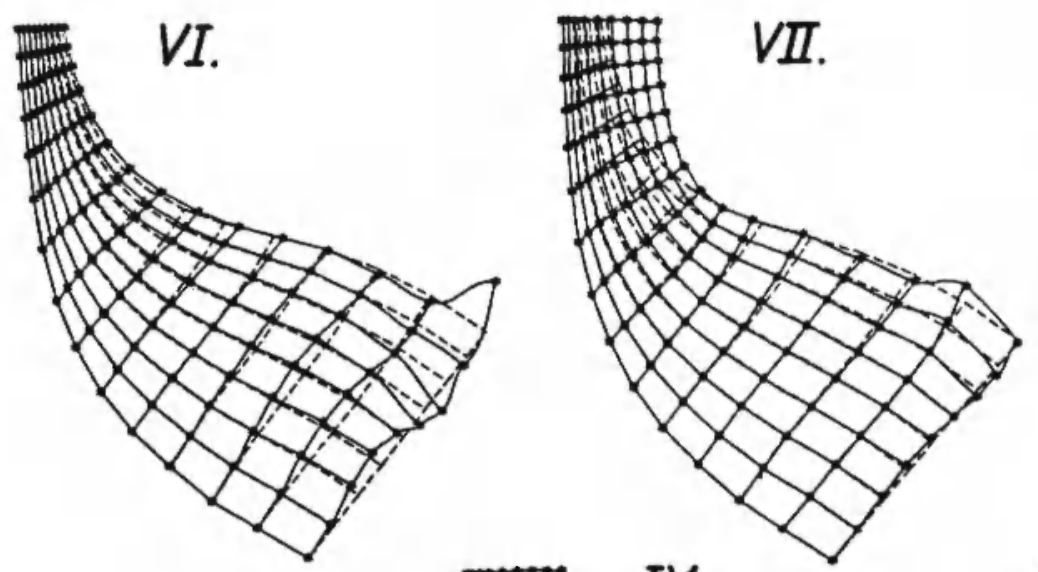

VIII.
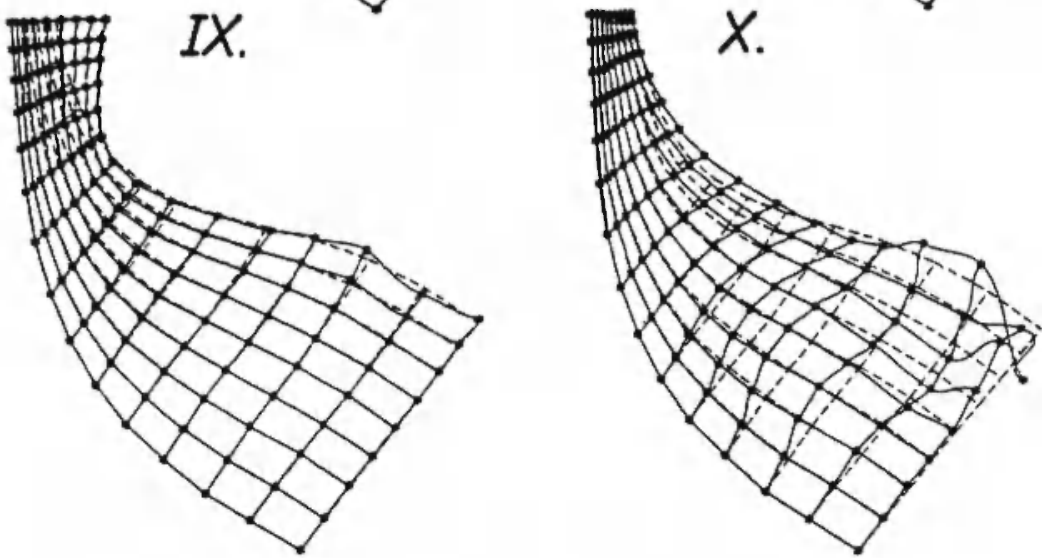

Fig. 3: Vibration modes of the radial blade considered

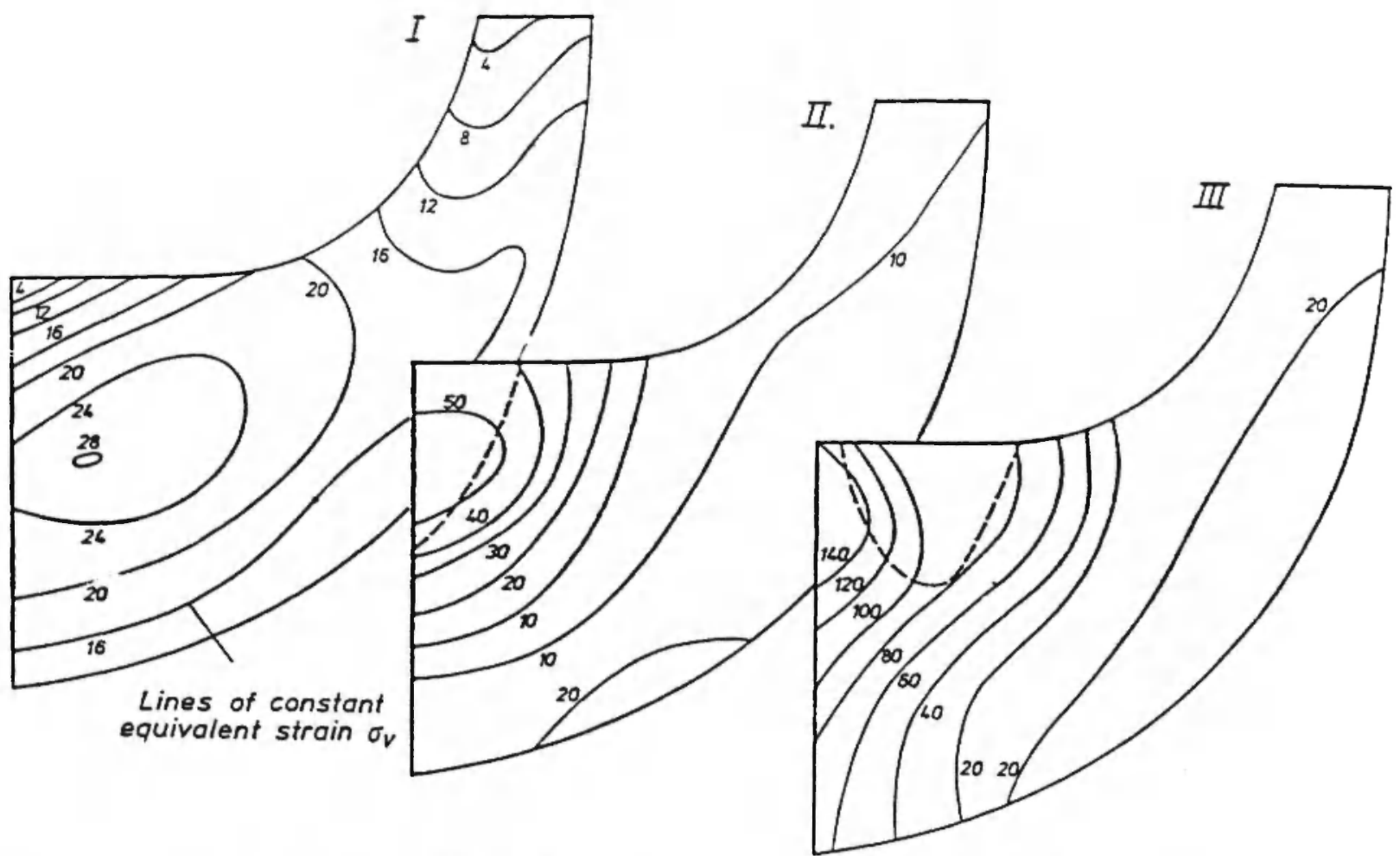

Fig. 4: Calculated equivalent strain distributions for vibration in the first three blade modes. Displacement of the blade inlet tip: $1 \mathrm{~mm}$ - - - node line. 


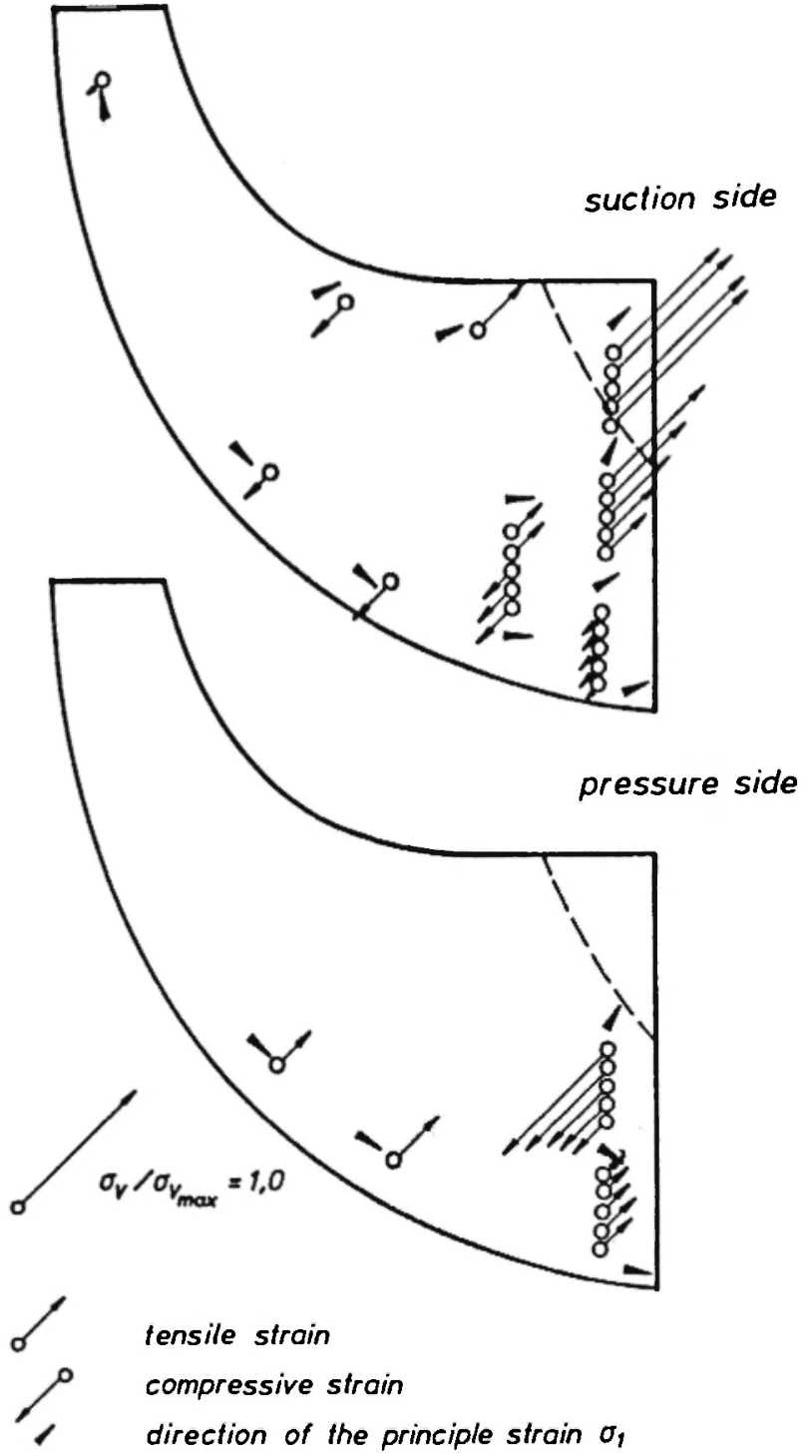

Fig. 5: Results of blade vibration tests with strain gages for the second blade mode. $\sigma_{\mathrm{V}}=$ equivalent stress; $\mathrm{f}=$ $1689 \mathrm{~Hz}$.

point of the blade and the small triangles indicate the direction of these strains. With the maximum strain value occurring at approximately $2 / 3$ of the blade height - and about half of the blade height for the first mode according to the results shown in $/ 5 /-$ these results confirm those obtained by the FE computations.

Another vibration test at rest was carried out to investigate the blade resonance behavior and the extent of interactions of the blades during vibration. In this measurement series, the impeller was excited in the range of the natural blade frequencies and the blade tip amplitudes were detected by a sound pickup. Typical results of these measurements are shown in Figure 6 for the vibration of one blade in the range of the first natural frequency. The occurrence of a spectrum of resonance peaks is the result of different natural blade frequencies due to manufacturing tolerances, and demonstrates the extent of interactions between the blades. Blade frequencies from $\mathrm{f}=782$ to $823 \mathrm{~Hz}$ were obtained by measuring the first natural frequencies of the different single blades of the impeller.

\section{Determination of Blade Damping}

An additional vibration test at rest was carried out to determine the damping properties of the different blades. This was achieved by an impulse excitation and by recording the vibrations as the amplitude decreased. An analysis of these results including a determination of the time required for decay of the vibrations enabled calculation of the decrement of damping. Figure 7 shows the results of these tests, indicating relatively low and very different values for the decrement of damping for the different blades. An additional test was carried out by rigidly fixing all but one of the impeller blades to prevent their vibration. The remaining blade was excited followed by measurement of its vibration characteristics. For this arrangement, higher values of the decrement of damping were obtained for most blades than with the test where all blades take part in the vibration (Fig. 7). In the test where all blades were free, it should be mentioned that beat effects could be observed with beat frequencies of $\mathrm{f}=2 \cdot 8 \mathrm{~Hz}$.

\section{Influence of the Blade Thickness}

A study of the influence of the blade thickness on the blade frequency was carried out and documented in $/ 12 /$; this concerns a problem which very often occurs in the stress design process. Usually values of blade thickness are chosen followed by calculation of the blade frequencies. The choice of blade thickness influences the occurrence of blade resonances. It is important to avoid resonances, particularly when the impeller blades are thin. A knowledge of how the increase or decrease of blade thickness influences a given blade frequency $f$ is required. For this purpose. series of FE calculations of blade frequencies were carried out for the test impeller with variation of the blade thickness by a thickness factor $\alpha$. By definition. 


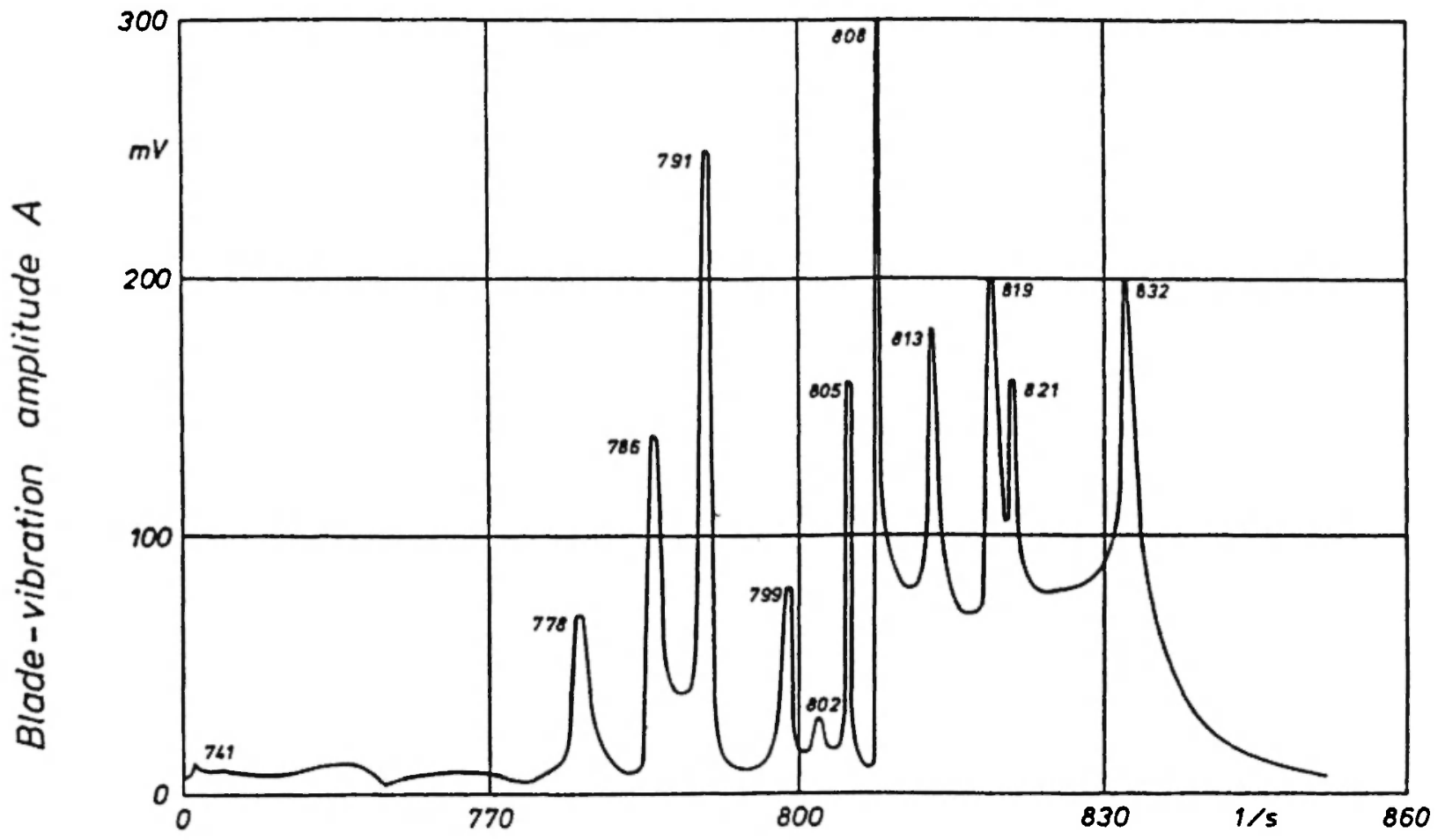

Blade vibration frequency $f$

Fig. 6: Vibration test at rest: Response of blade No. 18 of the 20 bladed impeller to a loudspeaker excitation in the range of the 1 st natural blade frequency. Measuring probe: sound pickup at blade tip of impeller inlet.

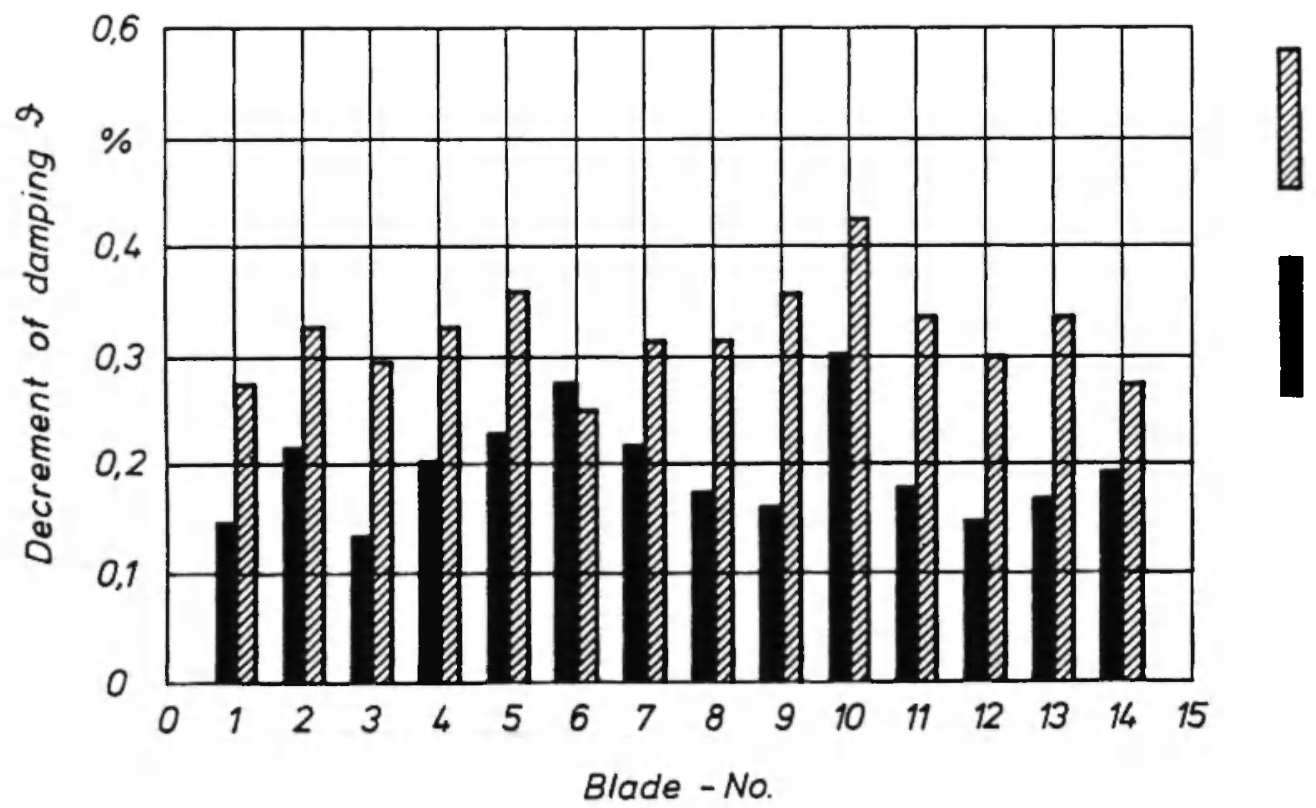

Other blades tightened

Free vibration of $c .1$ blades

Fig. 7: Damping properties of the blades of the test impeller. 
this value is 1,0 for the design value; a value of $\alpha=$ 0.9 , for example, means a 10 percent reduction of the thickness values of all the shell elements of the blade. The results for the first three modes are compared in Figure 8 with those obtained for the case of pure bending motion, eliminating the membrane stress.

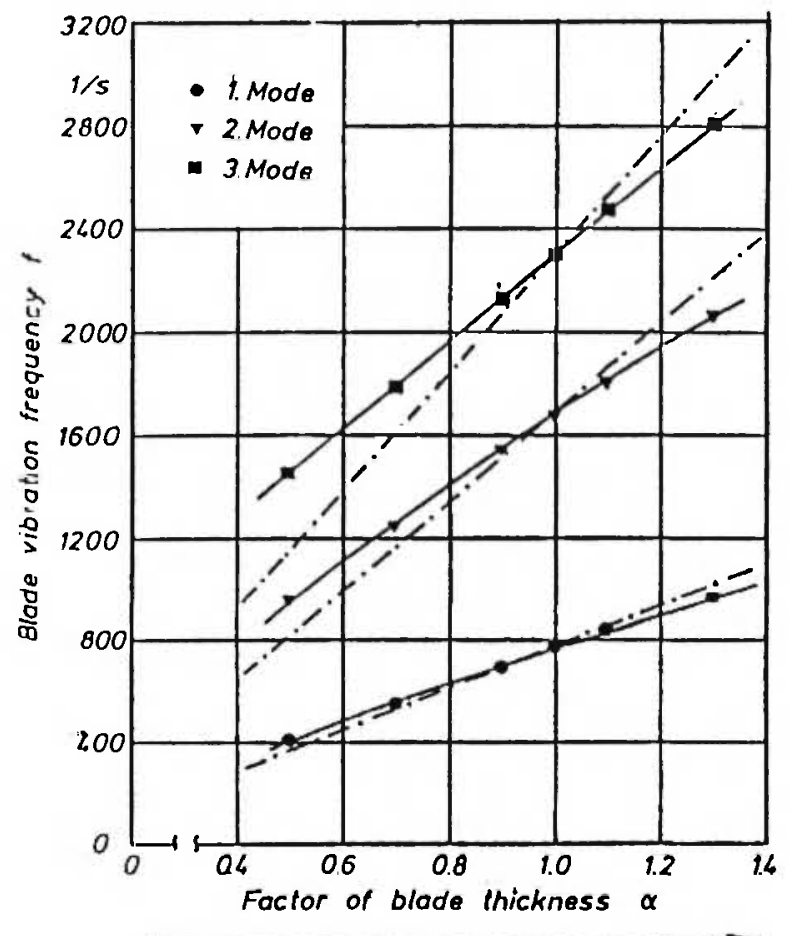

$-60-50-40-30-20-10 \quad 0+10+20+30$

Deviation from the design values $(\%)$

Fig. 8: Influence of the blade thickness on the first three blade frequencies. - FE calculation, bending and membrane stress; - pure bending stress, constant blade thickness.

The relationship $\mathrm{f} \sim \mathrm{h}$ can be used for the constant blade thickness $h$. The diagram illustrates the magnitude of error due to simplification compared with the results of the more accurate FE computations. There is a very small difference between the curves for the first mode because the vibration in this case is quite similar to a bending motion. As shown in the graph, the differences increase for higher modes, where the influence of the membrane stress becomes more significant.

\section{Test Facilities}

The test facilities for the experimental investigation are described in detail in /4/. As shown in Figure 9,

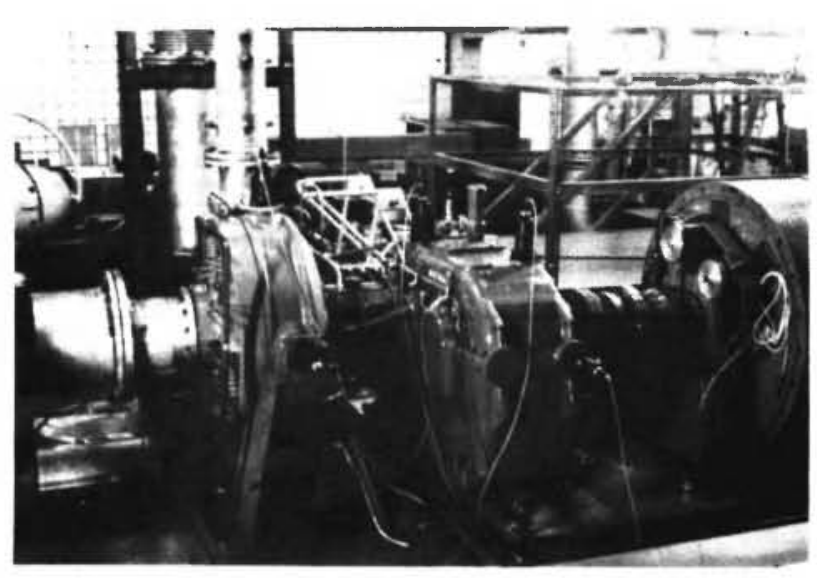

Fig. 9: Radial compressor test facility for the investigation of blade vibration.

the test rig consists of a $1350 \mathrm{~kW} \mathrm{DC}$ motor coupled to a gearbox which drives the centrifugal compressor. Fig. 10 shows a section of the compressor. The flow enters the compressor in an axial direction and passes the impeller and the long conical diffuser of constant radial flow area. It is collected downstream in a collecting chamber and leaves the compressor by the outlet tube which is tangential to the machine.

\section{Installation of a Multichannel Telemetry System}

Transmission of the blade vibration signals from the rotating shaft turned out to be a serious problem because slip-rings could not be used due to the high rotational speed of the compressor and the relatively large shaft diameter. Among the various useful transmission possibilities described in $/ 3 /$, a telemetry system was selected and first test results with a battery-powered 1 -channel system proved very successful. At that time, the considerable differences in the vibration behavior of the different blades of the impeller had already been observed; this effect was investigated in more detail during the current research. Accordingly, it was necessary to get information from more than one blade, leading to the requirement for a multichannel telemetry system.

The installation of the telemetry system took quite a long time and demonstrated that the development of such multichannel systems under ambient conditions such as high temperature, high acceleration, the presence of oil and with only little space for the components was not sufficiently advanced. The use of multichannel telemetry installations for turbomachines - albeit of very small size - has only been 


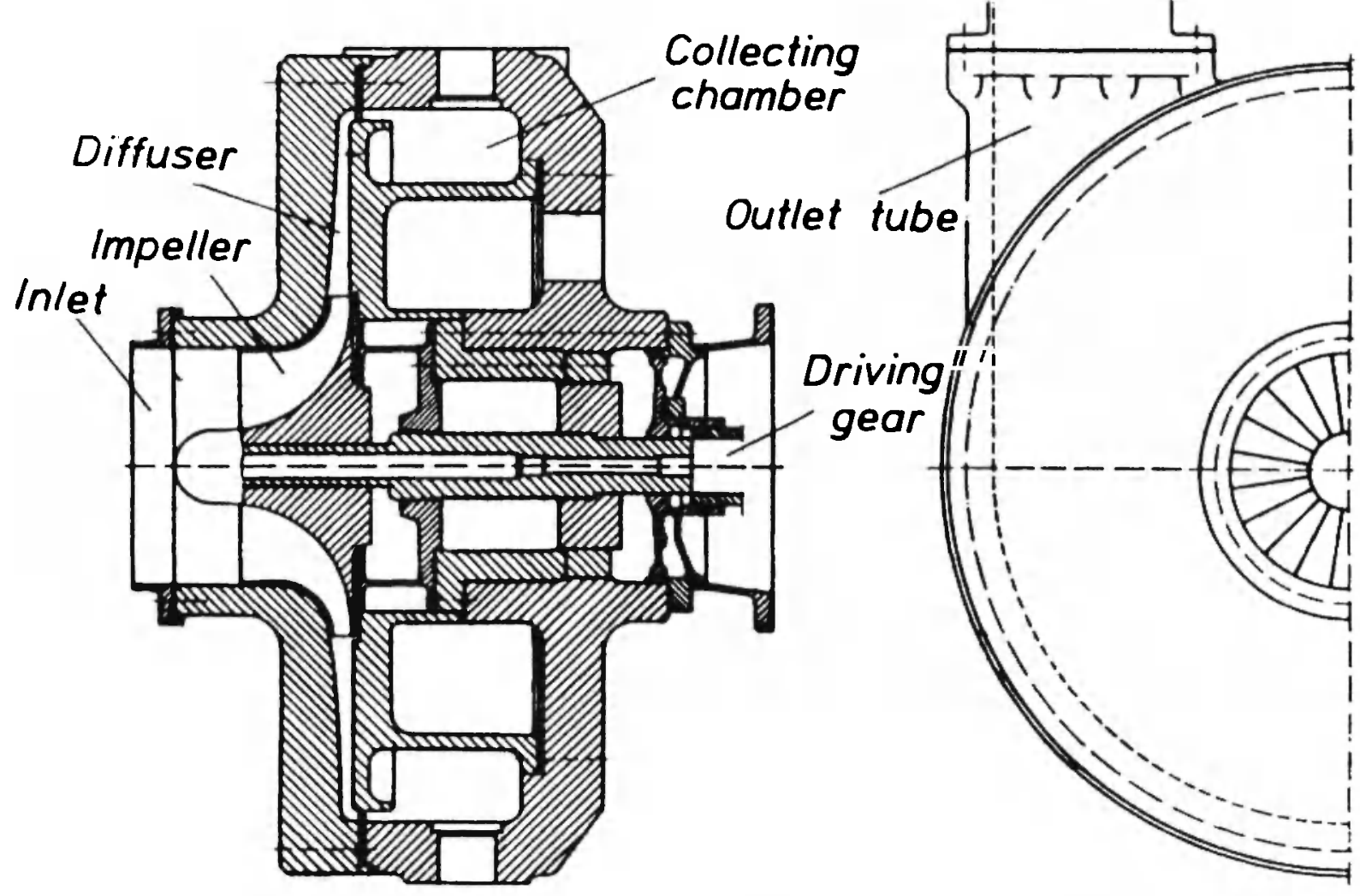

Fig. 10: Sectional view of the test compressor.

reported in recent publications such as $/ 9 /, / 10 /$ and $/ 11 /$.

One necessary test may demonstrate the great amount of work which had to be done for the installation of the telemetry system. Temperature color gage measurements were carried out in the hollow shaft of the impeller during operation of the compressor to determine the temperature distribution in this region, which is heated by the bearing. This was necessary to ensure that the temperature in the shaft is suitable for the transmitter, which only tolerates a maximum temperature of $100-120^{\circ} \mathrm{C}$. The results of these measurements at different locations in the shaft at $n=19000 \mathrm{rpm}$ are shown in Figure 11. Considering operation of the compressor at higher rotational speed for example at $n=22000$ $\mathrm{rpm}$, the maximum extent of the installed transmitter in the hollow shaft is limited to the region between measuring points 3 and 4 . Due to the size of the transmitter, a new and longer hub section had to be designed and installed in the impeller (Figs. 1 and 12). Further tests were carried out with respect to the durability of the rotating coil for the inductive power supply; the latter was considered to be necessary

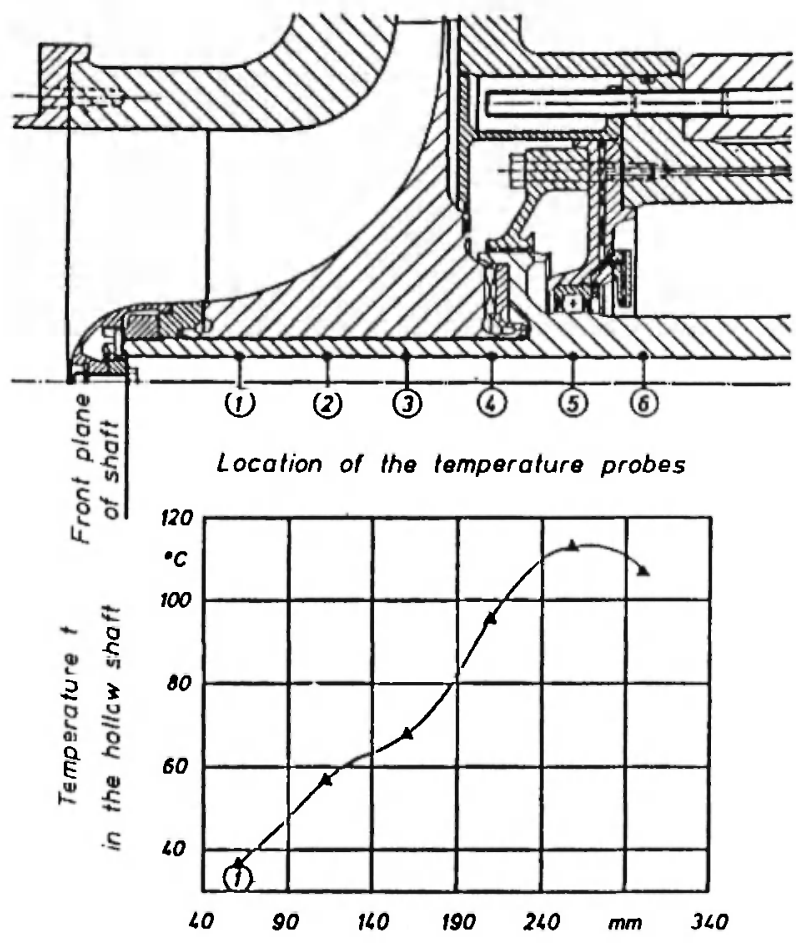

Distances from front plane of shaft

Fig. 11: Results of temperature measurements in the hollow shaft of the radial compressor by means of color gages at $\mathrm{n}=19000 \mathrm{rpm}$. 

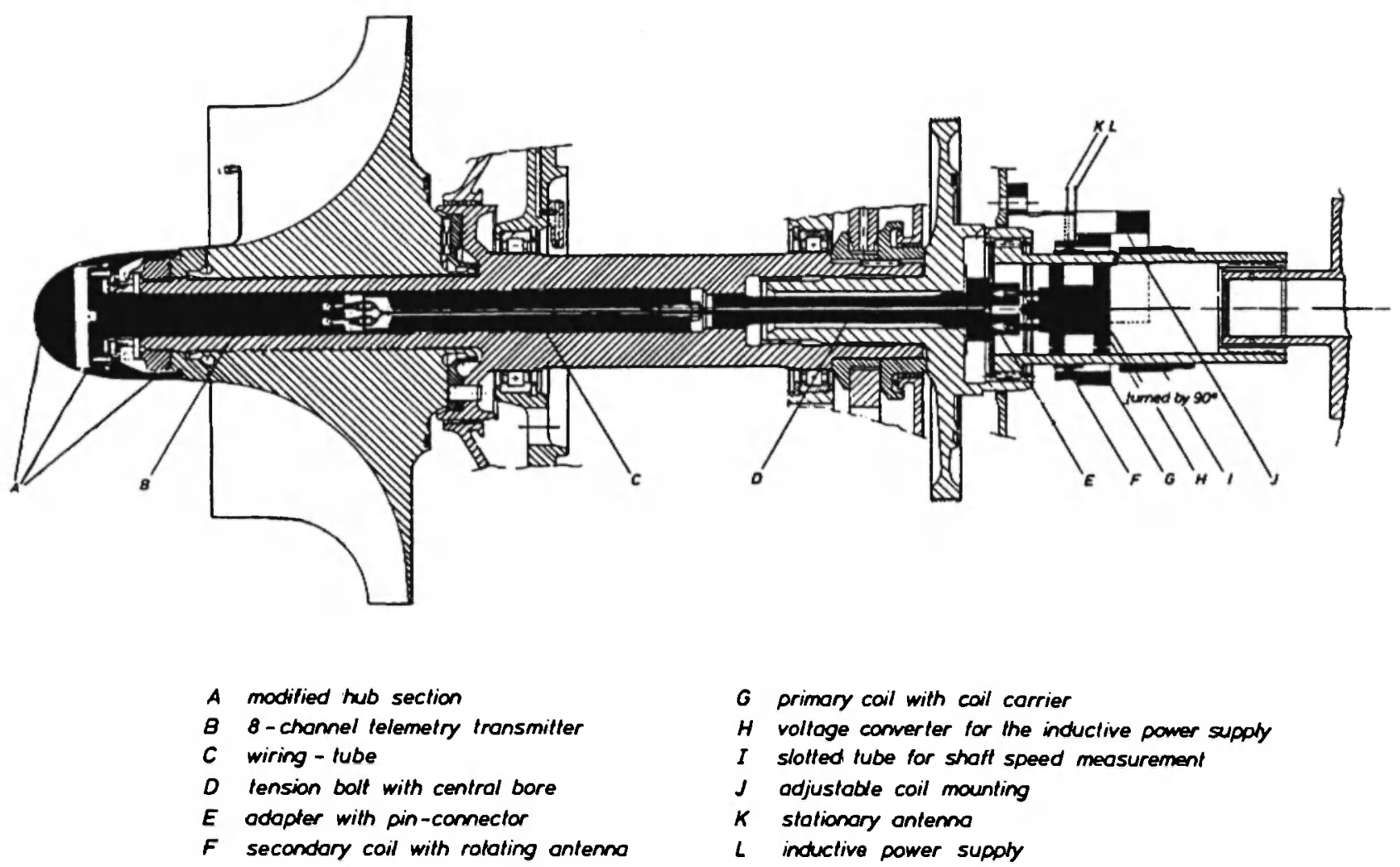

Fig. 12: Centrifugal compressor with installations for the telemetry transmission.

because a battery supply for the transmitter would not stand up to the high temperatures shown in Figure 11.

The principle of the 8-channel telemetry system used - described in detail in $/ 13 /$ - is illustrated in Figure 13. The different signals are transformed to frequencies which are modulated onto a carrier frequency. After transmission through the same coil system used by the inductive power supply, the different signals of the multichannel system are separated again by means of electronic filters.

Figure 12 - a sectional view of the compressor shows the installation of the telemetry system with the new components of the signal transmission system shaded in black. The transmitter with its plate and the contacts to the strain gages is situated in the bore of the impeller shaft, as can be seen in the photo in Figure 14 taken during assembly of the transmitter. It is connected with the components of the inductive power supply which are mounted in the socket tube coupling between the compresser and the gearbox. To facilitate frequent assembly and disassembly, all parts had to be constructed with plugs and sockets. The vibration signals leave the transmitter through

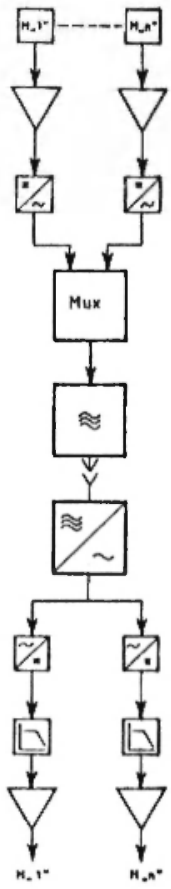

('robe, Pick- up (strain-gage)
Amplifier
Signal transformation
(Voltage/frequency-transformation)
Function of signals
(Frequency multiplex)
Transmilter
Receiver (Amplifier. Demodulation)
Reconversion (Separation of channels, fre-
quency (Voltage reconversion)
Filter (low - poss, variable)
Signal transformalion
(Amplifiar,Recording process, storage,printing)

Fig. 13: Operation principle of the 8-channel telemetry system for the transmission of blade vibration signals. 


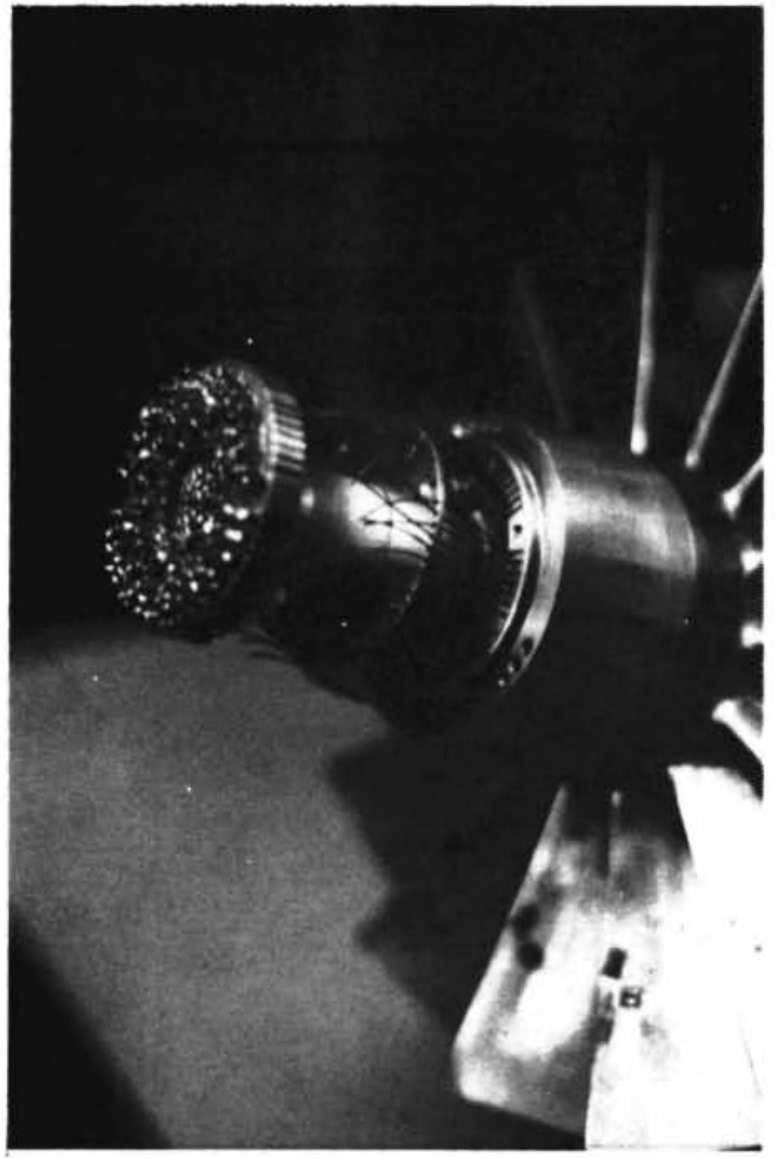

Fig. 14: Radial impeller during assembly showing wiring of the 8-channel telemetry transmitter.

the wiring of the power supply and are transmitted via the coil system of the inductive link. A view of this part of the installation is shown in $/ 5 /$ and $/ 12 /$. Finally, the use of an adjustable receiver antenna rather than the stationary antenna would probably improve the transmission quality. The FM transmission has proved to have good reliability for speeds up to $22000 \mathrm{rpm}$.

\section{Calibration}

A lot of work was necessary with respect to calibration of the measuring chain to ensure sufficient accuracy of the measurements and the transmission. The frequency response characteristic of each channel of the telemetry system was recorded in order to be able to allow for it in the analysis of the signals. However, the semiconductor strain gages caused most of the calibration work. In preparatory tests, considerable deviations of the sensitivity factors were observed due to manufacturing tolerances and especially due to differences in the fixation. Dynamic calibration tests were necessary whereby vibration signals from semiconductor strain gages were compared with data from foil strain gages attached to the blade directly adjacent. Such tests allowed a more exact sensitivity factor for each semiconductor strain gage to be obtained.

\section{Results of Blade Vibration Measurements}

\section{Blade Vibration at Constant Rotational Speed and Various Throttle Valve Positions}

Initially, blade vibration measurements were carried out at constant rotational speed and various mass flow rates. In Figure 15, results removed from resonance points are plotted in the compressor chart as black bars, with the length indicating the stress amplitude $\epsilon$ in $\mathrm{mm} / \mathrm{m}=\%=1000 \mu$ strain. It should be mentioned that no measurements were carried out between $\mathrm{n}=17500$ and $18000 \mathrm{rpm}$ because a resonance between the blade frequency at that speed and the third engine order occurs in this range. Small deviations of the rotational speed that commonly occur during the time measurements are recorded cause considerable differences in blade excitation. Further, safety reasons made it necessary to restrict the operating range of the compressor in the region of the occurrence of rotating stall and surge to speeds below $\mathrm{n}=14000 \mathrm{rpm}$.

Results in Figure 15 show increasing intensity of blade excitation towards higher values of rotational speed due to the effect of increasing forces in the flow. A strong increment in blade excitation can be observed to maximize over a wide range of mass flow when the compressor is driven from choke towards surge at a constant rotational speed.

In this range, the vibration signals have a very stochastic nature and strong indications of a stalled flow, while periodic vibration with one dominant frequency can be observed when resonance occurs. The blade vibration stress amplitudes decreased again to a varying degree before the surge point of the compressor.

An explanation of the observed blade vibration behavior was obtained by carrying out additional wall pressure measurements in the shroud in the impeller region. The results, documented in $/ 8 /$ and $/ 12 /$, showed the occurrence of strong pressure fluctuations in the operating point of the compressor with 


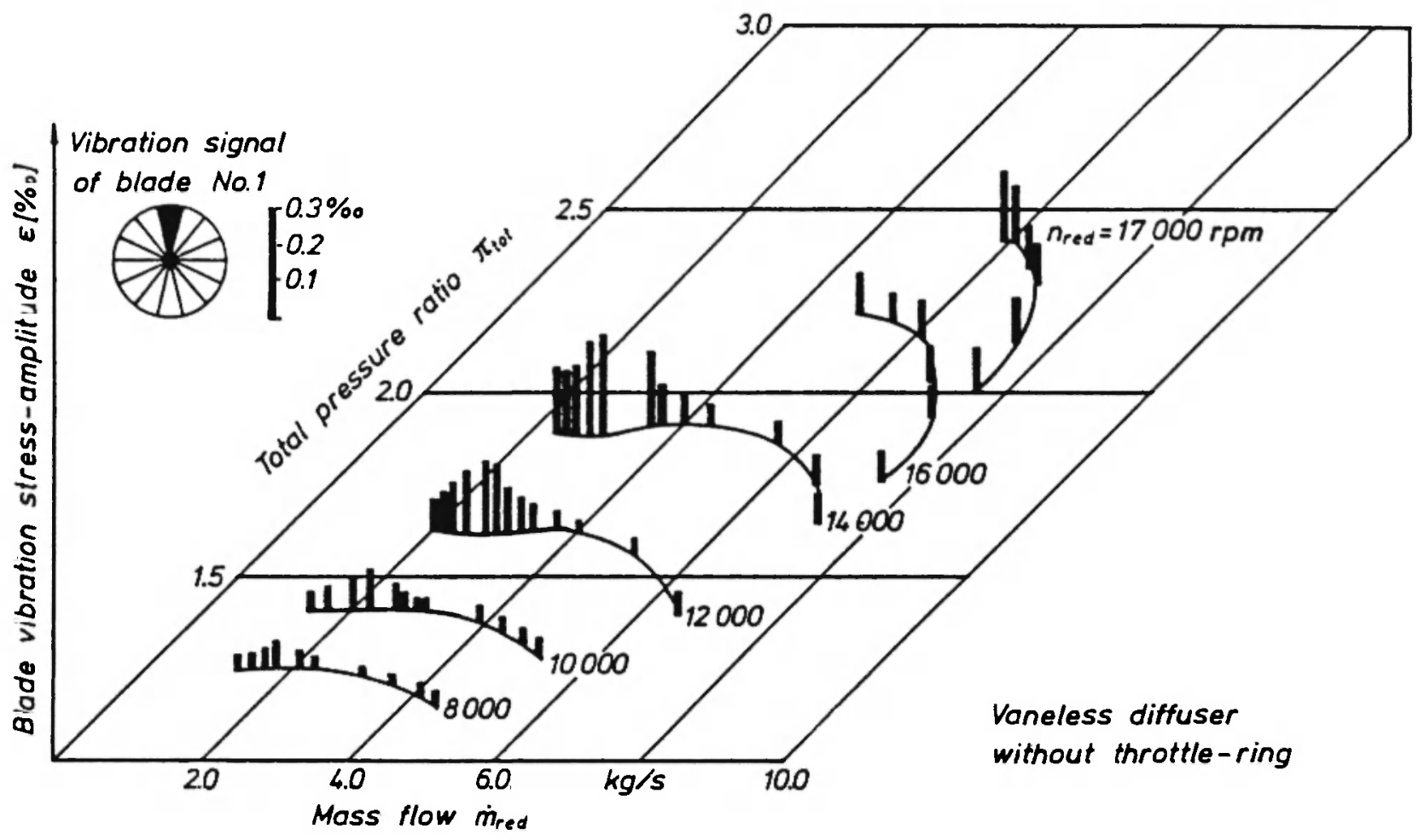

Fig. 15: Blade vibration at constant rotational speed and various valve positions.

increased blade vibration. Parallel measurements of the inlet flow angle enabled an explanation for the strong blade excitation visible in Figure 15 for low mass flow rates. When closing the throttle valve at constant rotational speed and turning from the choke to the surge line in the middle of the mass flow range, stall occurs in the inlet tip region. This is the reason for a sudden change of the inlet flow angle from about $\alpha=20$ to $\alpha=90$, indicating the occurrence of a fluctuating peripheral flow in the compressor inlet in the wall zone. Further closing of the throttle valve leads to inlet angles of $\alpha=110$ indicating a reverse flow in the tip region which increases with lower values of mass flow and becomes more and more stable. The reduced pressure fluctuations in this zone result in lower blade excitation near the surge line. A consideration of the signals of 6 blades as documented in $/ 12 /$ showed that blade excitation due to stall effects results in vibration stresses in the different blades of nearly the same amount. This is quite a different excitation behavior from that observed in the cases of resonance vibrations, where the blades vibrate at very different intensities. This will be demonstrated later on.

It should still be mentioned that even in operating points of the compressor in unstalled ranges, the blade vibration signals show a very fluctuating nature with considerable variations of the amplitude. Whereas Fig. 15 shows RMS values of the blade stress signal, Fig. 16 compares values of blade vibration obtained with other analysis methods. For the rotational speed of $\mathrm{n}=12000$ and $14000 \mathrm{rpm}$, the blade vibration stress amplitude is plotted against the mass flow; curves of RMS values and data of a "peak" measurement are shown. A third curve represents the maximum values of stress in the peak measurements; they also show a fluctuating nature. It can be demonstrated that, for a given RMS result stress, amplitudes twice or three times greater can be observed mainly as short stress peaks in the fluctuating blade vibration signal. It should be mentioned that RMS and maximum peak values agree much more closely in the case of resonance vibration due to the periodic nature of the blade signal.

\section{Blade Vibration with Increasing Rotational Speed at} Constant Throttle Valve Position

Blade vibration measurements were carried out in the whole rotational speed range of the compressor. It was naturally interesting to get results of maximum stress at resonance points, but the main emphasis was 


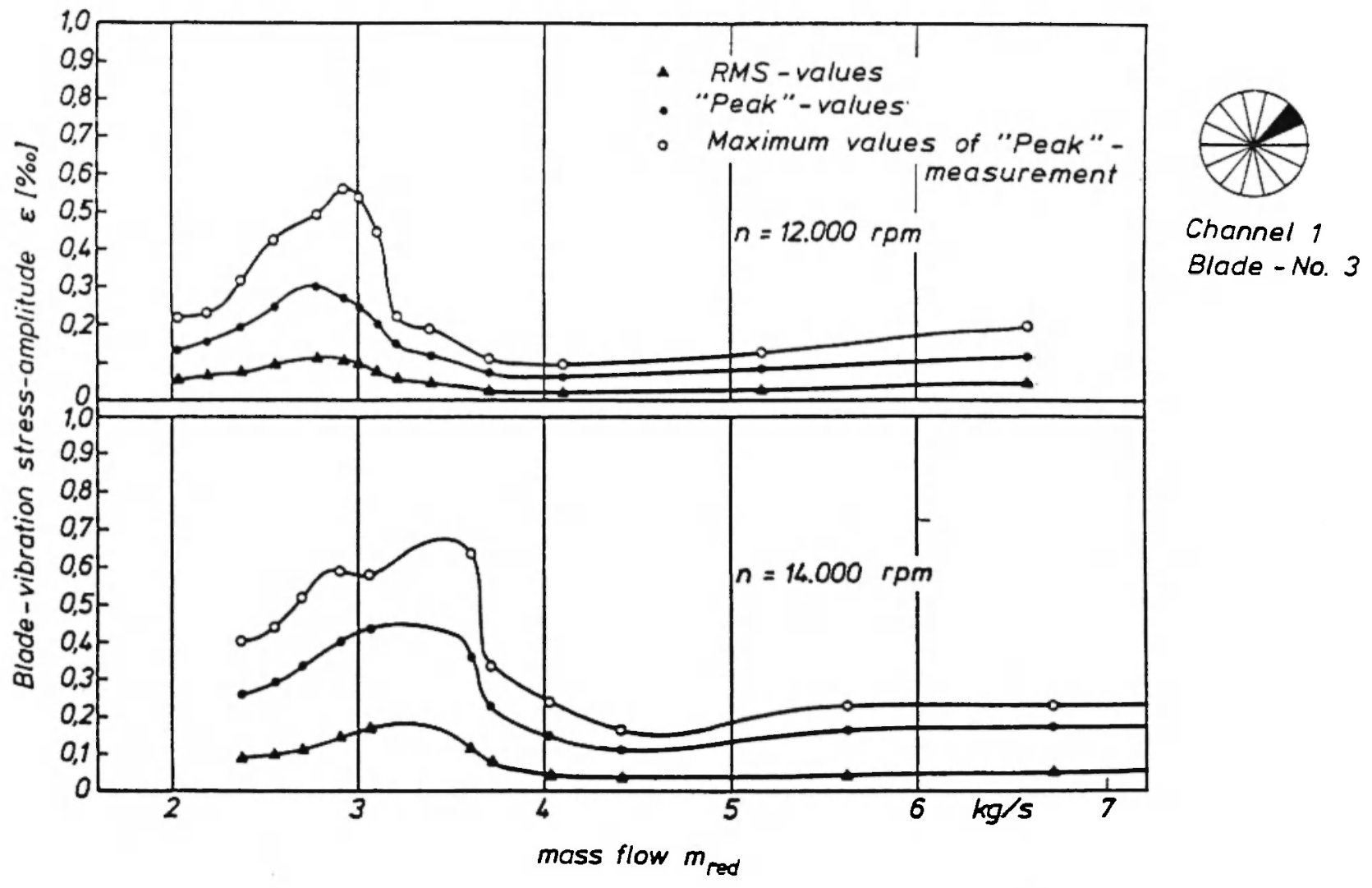

Impeller: 28 blades

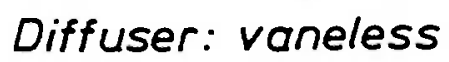

Fig. 16: Comparison of blade vibration amplitudes at constant rotational speed obtained by different analysis methods.

placed on an investigation of the excitation mechanisms. Subjects of interest were quantitative deter. mination of the excitation and investigation of the extent of decrease of blade vibration if the intensity of excitation is reduced. Such questions, which relate to practical aspects in the stress design of radial impellers were considered to be very important and were treated in /14/.

In contrast to conditions in axial compressors, the non-uniformity of the flow in the diffuser of a radial compressor due to the influence of the outlet tube is a significant factor for the excitation of blade vibration. This non-uniformity can even be observed close to the compressor inlet, where the rotating blades pass these pressure gradients and where the blades are sensitive to excitation. Figure 17 shows the results of pressure measurements in the vaneless diffuser with a circumferential distribution of the measuring points and for various mass flow rates at two different radius positions. In this diagram, $\lambda_{D}$ signifies the radius ratio $D / D_{2}$, where $D_{2}$ is the diameter of the impeller. The magnitude of pressure drop for all curves at approximately $270^{\circ}$, just in the position of the outlet tube, shows a considerable non-uniformity of the flow in this region. A surprising effect is that the mentioned pressure drop has a sharper configuration at $\lambda_{D}=1,23$ in the region behind the impeller than in the diffuser at $\lambda_{D}=1,83$. It can be expected that a similar pressure distribution will extend into the impeller region, and will be the reason for the excitation of blade vibration.

More uniform flow conditions as shown in Figure 18 , indicating only very little influence of the outlet tube, could be obtained by using a throttle ring in the diffuser; this was demonstrated in /14/. Blade vibration measurements were carried out with both configurations to investigate the difference in blade excitation.

Results of blade vibration measurements are shown in Figure 19 for 1 blade and 1 splitter blade for the compressor with and without throttle ring. The blade vibration stress amplitude is plotted for the whole rotational speed range from $n=5000$ to $19000 \mathrm{rpm}$ 


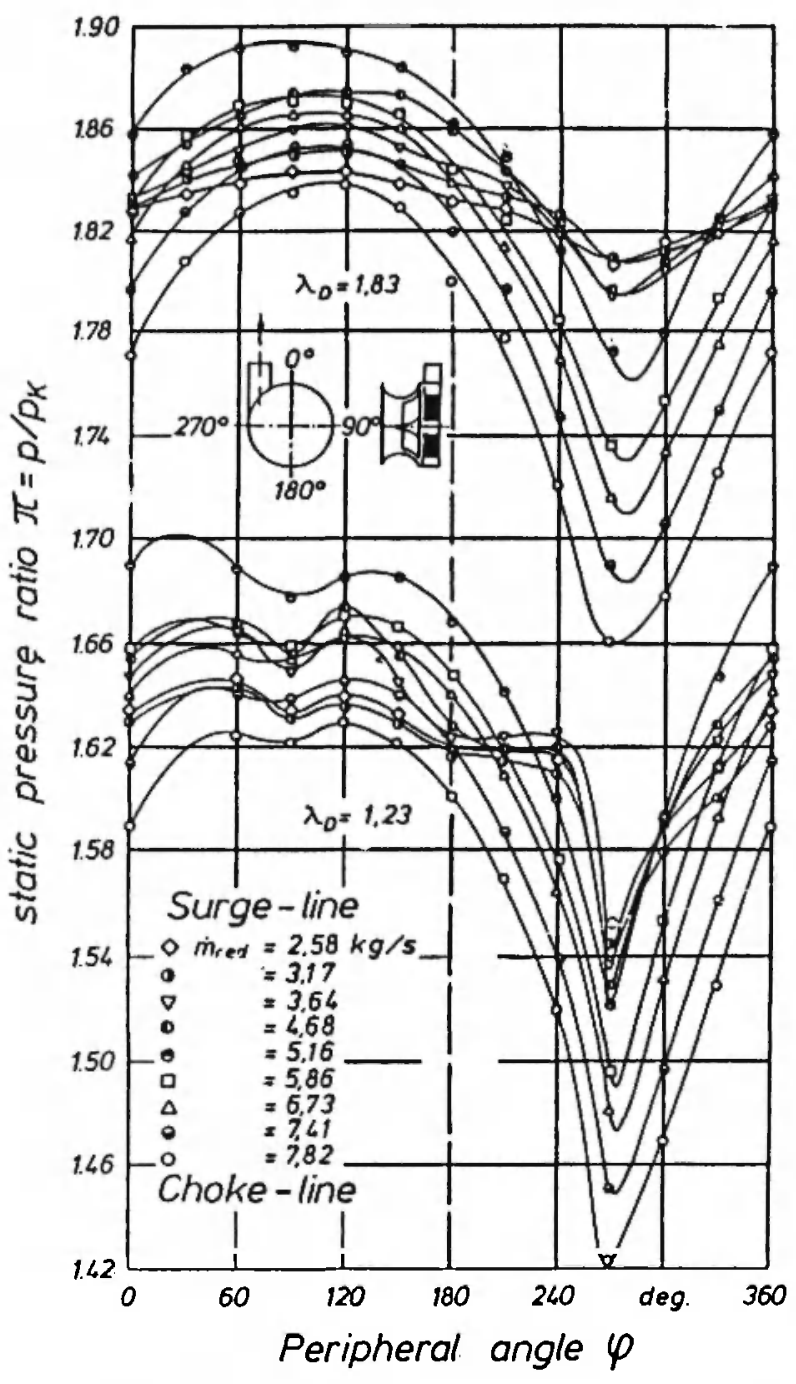

Fig. 17: Peripheral distribution of the static pressure ratio in the vaneless diffuser of the compressor $(20$ blades) at $n=14400 \mathrm{rpm} . \lambda_{D}=$ Radius ratio $\mathrm{r} / \mathrm{r}_{2}$; $r_{2}=$ Radius of impeller.

for operating line near the choke line of the compressor. The peaks in the curves signify resonances between the lower blade frequencies and the engine orders. Up to $n=17000 \mathrm{rpm}$, nearly no difference in the stress amplitude can be observed. Comparing the values of the different peaks, only the resonance point at $n=18000 \mathrm{rpm}$ shows slightly lower blade excitation for the configuration with the throttle ring. It is surprising that only very small differences in the blade vibration amplitudes were obtained for uniform and non-uniform pressure conditions in the diffuser; in other words, even a better aerodynamic design of the compressor outlet would not result in lower values of blade vibration stress at resonance points.
Excitation Due to the Non-Uniformity of the Flow in the Compressor Inlet

In the design of radial impellers, blade frequencies are usually calculated to avoid resonances due to an excitation from the inlet, especially in those cases when bearing flanges are mounted in front of the impeller or when non-uniformities of the inlet flow due to other reasons are expected. It was hoped to find out the magnitude of blade excitation due to this effect. For this purpose, three spoilers as shown in Figure 20 were mounted in the compressor inlet to simulate bearing flanges. First of all, the influence of the spoilers on the velocity distribution in two planes before the impeller inlet was measured at a rotational speed of $n=18000 \mathrm{rpm}$. The results of these flow measurements are shown in Figure 21. A sharp inlet flow velocity drop due to the profiles was still observed $10 \mathrm{~mm}$ in front of the impeller, indicating powerful excitation of the blades with a very small peripheral extension.

Blade vibration data for this configuration, once again for constant throttle valve position, maximum mass flow and various rotational speeds, are shown in Figure 22. The influence of the spoilers can be evaluated by comparing this diagram with Figure 19, which shows the results obtained without spoilers. The curve for the blade vibration stress amplitude in Figure 22 is characterized by clearer and stronger resonance peaks than in Figure 4. Up to $n=17000$ rpm, most of the resonance peaks are higher than in Figure 19, but remain under a stress level of $\epsilon \approx$ $0.15 \%$, which is not considered to be dangerous. Only the resonance point at $n=18000$ rpm shows stronger blade vibration for the configuration with the spoilers. According to an analysis of the blade vibration signals in a Campbell diagram in $/ 14 /$, the three profiles in the compressor inlet are the cause for an excitation of the 3rd and 6th engine orders, coming to resonance with the I and II blade frequencies in a small speed range. Although this excitation effect is observable, it can be concluded that even sharp non-uniformities of the flow in the inlet with a very symmetrical position result in only very little increase in the intensity of blade excitation. This result corresponds to further observations which were made on various compressors, for example, with blades in the inlet for throttling the compressor or with bearing flanges. 


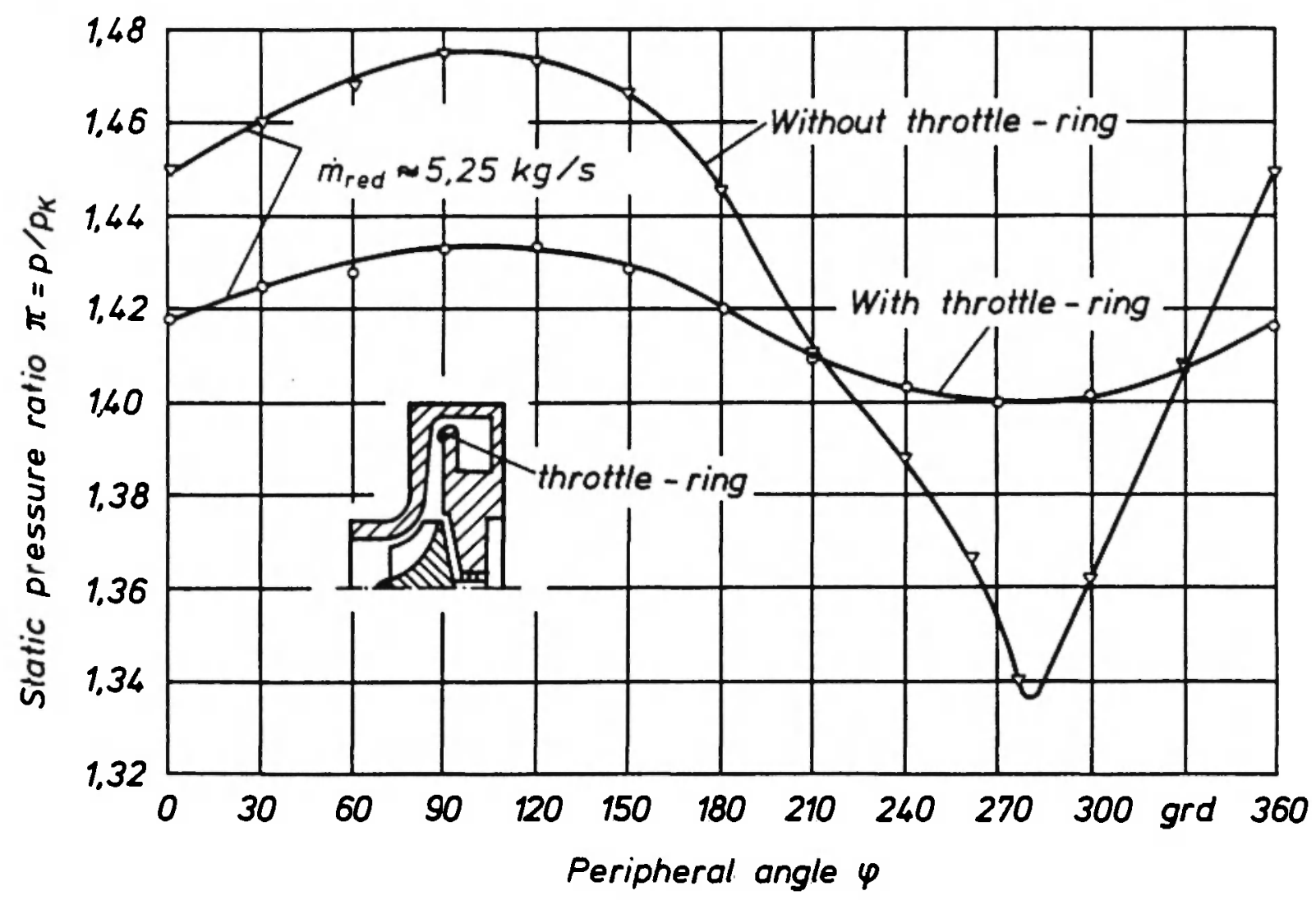

Fig. 18: Comparison of peripheral static pressure distributions in the diffuser with and without throttle ring. Diameter of measuring points in the diffuser: $\lambda_{D}=D / D_{\hat{i}}=1.23\left(D_{2}=\right.$ diameter of the impeller), $n=12000 \mathrm{rpm}$.

\section{Conclusions}

Results of an investigation of blade vibration on a high pressure ratio / high mass flow centrifugal compressor with thin blades were described. FE calculations and vibration tests at rest were carried out to determine the locations of the attachment points for the strain gages. FE computations were also used to calculate the static stress due to centrifugal forces, and to obtain information on the influence of the blade thickness on the natural frequencies of the radial blades. Additional experiments yielded data on blade damping properties. An 8-channel telemetry system was used for the transmission of the signals from the rotor. The preparatory tests, rig installation and calibration are also described.

Results of blade vibration measurements are presented for constant rotational speed and various mass flow rates with characteristic stall effects in the impeller inlet tip region resulting in considerable blade excitation.
Flow and blade vibration measurements wère used to investigate the influence on blade excitation of a non-uniform flow distribution caused by the outlet tube and by spoilers in the compressor inlet. The results presented show that different pressure conditions in the diffuser with both uniform and non-uniform peripheral distribution have very little influence on the magnitude of blade resonance stress amplitudes. A similar result was obtained by installing spoilers in the flow channel in front of the impeller. In this case, the intensity of blade excitation increases less than that expected, and only reaches stress amplitudes which are not considered to be dangerous.

\section{Acknowledgements}

The research described in this paper was funded by the German Research Association (DFG) and the Forschungsvereinigung Verbrennungskraftmaschinen e.V. (FVV). The authors would like to thank them for their support. 

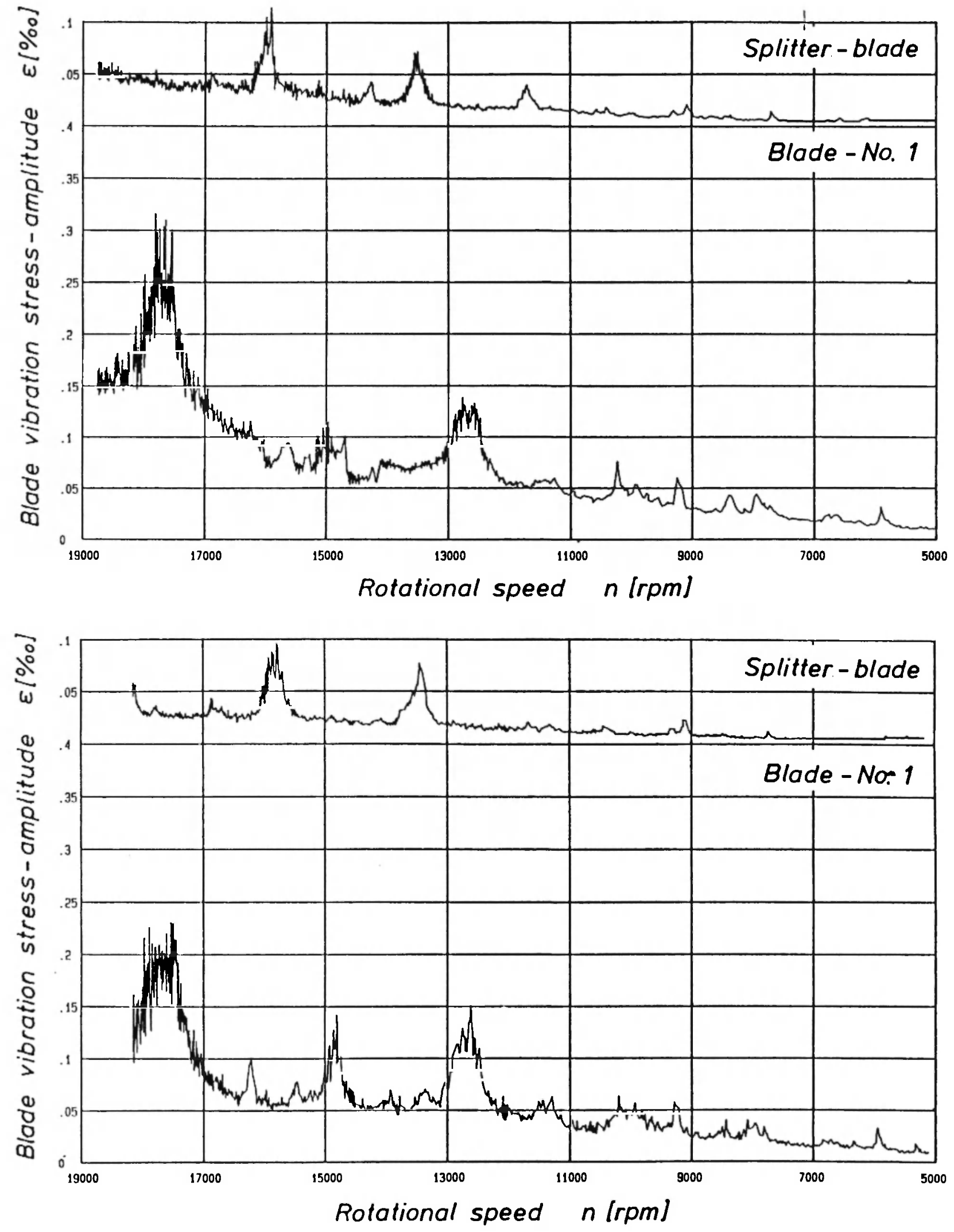

Fig. 19: Comparison of blade vibration stress amplitudes for 2 blades in the whole speed range of the compressor with and without throttle ring; operating line near choke line. 


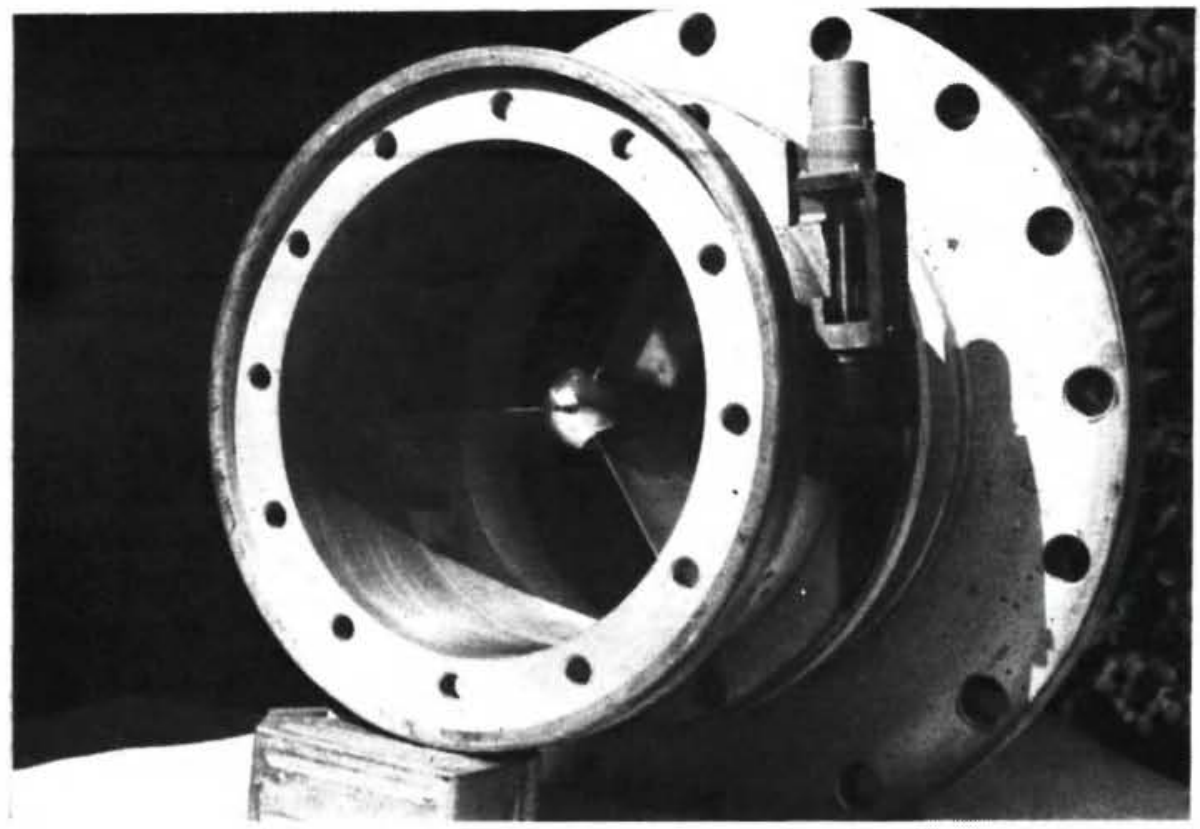

Fig. 20: View of spoilers in the compressor inlet.

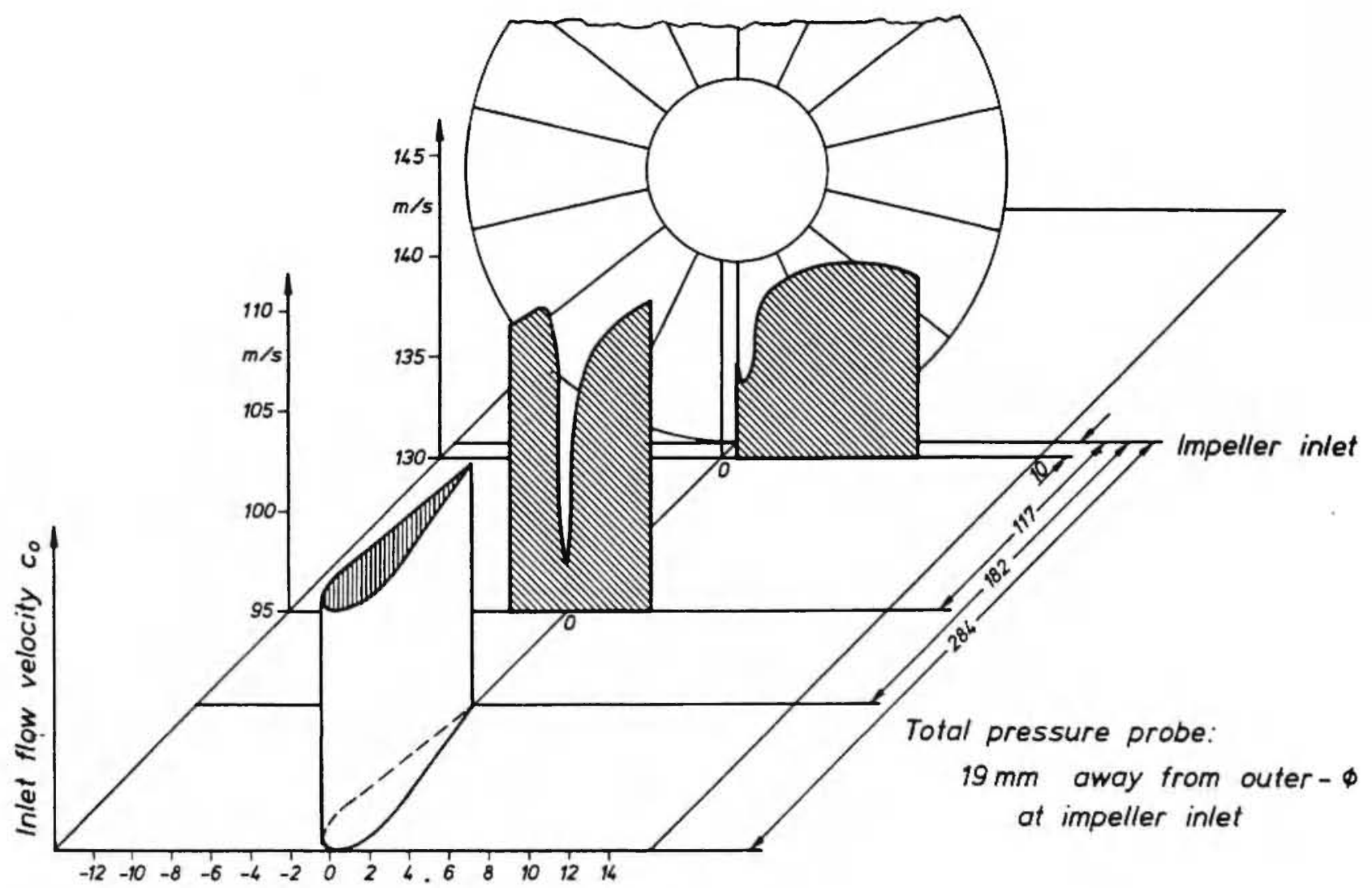

Peripheral coordinate $\times[\mathrm{cm}]$ at impeller inlet

Fig. 21: Inlet flow velocity distribution due to spoilers mounted in the compressor inlet; $n=18000 \mathrm{rpm}$. 


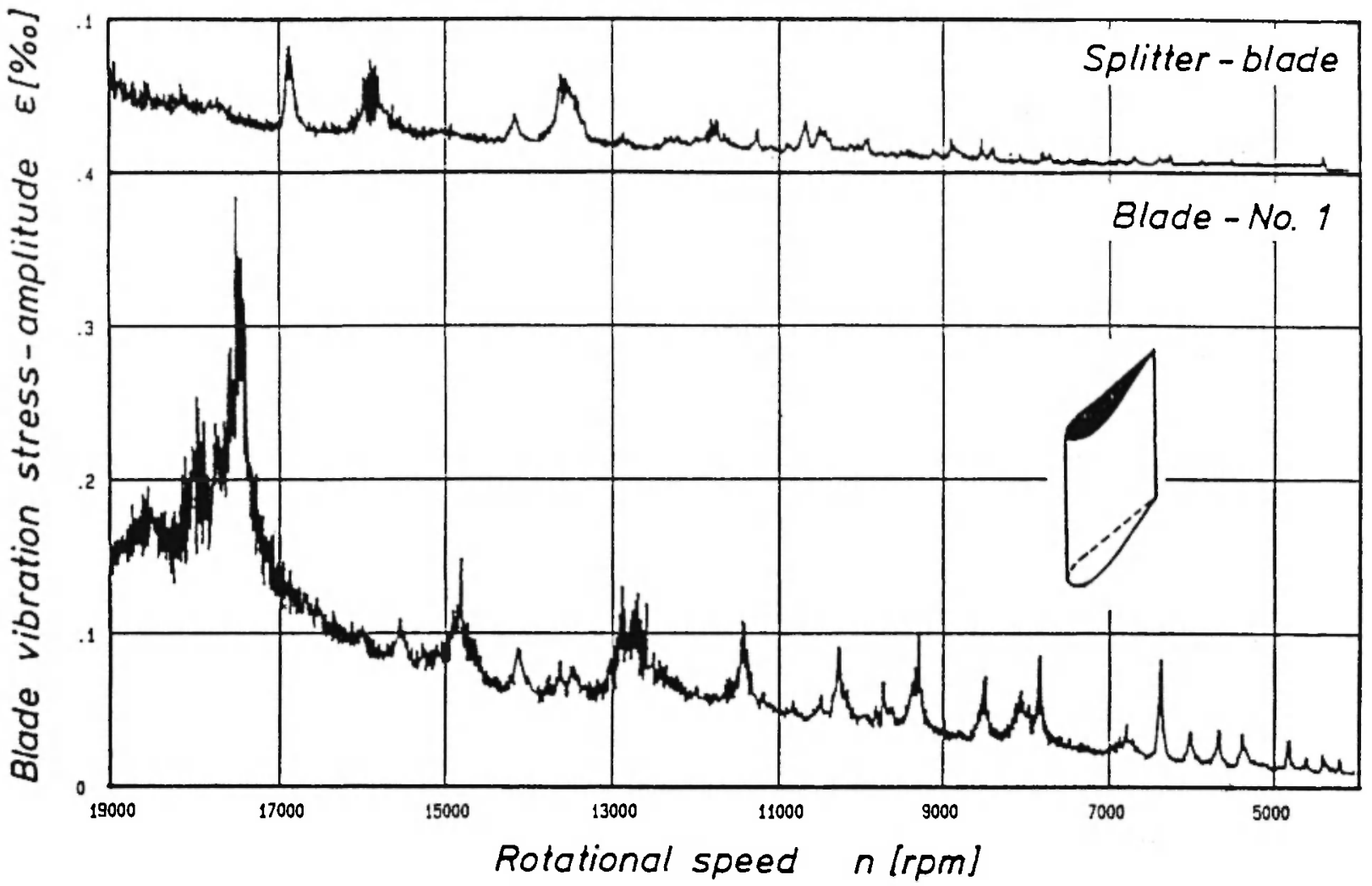

Fig. 22: Blade vibration with a compressor with 3 spoilers mounted in the compressor inlet; operating line near choke line; vaneless diffuser with throttle ring.

The help of Dr. Jäger in the preparation of the work, of Dr. Kreitlow and Dipl.-Ing. Geldmacher in the optical investigations, of Dr. Kassens and Dipl.-Ing. Hasemann in the signal analysis and of Mr.v. Lueder and Mr. Tanneberg in the experiments is also gratefully acknowledged.

\section{References}

1. U. Haupt, K. Bammert and M. Rautenberg, "Blade Vibration on Centrifugal Compressors Blade Response to Different Excitation Conditions", Int. Gas Turbine Conference of the ASME, Houston/Texas, 1985.

2. U. Hass, U. Haupt, M. Jansen, K. Kassens, P. Knapp, M. Rautenberg and W. Wittekindt, "Angewandte Messtechnik bei der Untersuchung zeitlich veränderlicher Strömungsvorgänge in Radialverdichtern", Atomkernenergie (ATKE) Bd. 32 (1978) Lfg. 4, S. 308-314.

3. U. Haupt and M. Rautenberg, "Zur Untersuchung von Schaufelschwingungen an Laufrädern hoch- belasteter Radialverdichter mittels Datentelemetrie", MTZ 39, Vol. 4, 1978, S. 177. 183.

4. K. Bammert et al., "Untersuchung der Laufradströmung in hochbelasteten Radialverdichterrädern", Forschungsberichte Verbrennungskraftmaschinen, Heft 155, 1974.

5. U. Haupt and M. Rautenberg, "Investigation of Blade Vibration of Radial Impellers by Means of Telemetry and Holographic Interferometry", Journal of Engineering for Power, Vol. 104, ASME-Paper No. 82-GT-34, Int. Gas Turbine Conference of the ASME, London, 1982.

6. U. Haupt and M. Rautenberg, "Schaufelschwingungen àn Laufrädern hochbelasteter Radialverdichter", MTZ 44, Vol. 4, 1983, S. 123. 129.

7. W. Fister and H. Heiderich, "Untersuchungen über den Einfluss von einigen geometrischen Parametern auf den Verformungs-und Spannungszustand von Radialverdichterlaufrädern", VDI . Berichte Nr. 264, 1976.

8. U. Haupt, H. Kreitlow and M. Rautenberg, "Blade Vibration Measurements by Means of 
Telemetry and Holographic Interferometry on a Radial Impeller with Thin Blades", Fourth International Conference for Mechanical Power Engineering, Cairo, October, 1982.

9. W.M.Krassick, "The Development of a Miniature, High Speed Telemetry System for Dynamic Stress Analysis", Journal of Engineering for Power, 1968, pp. $55 \cdot 64$.

10. R.D. De Rose, "Low Profile Strain Gage Applications Telemetered from Rotating Machinery", Joint Fluids Engineering/Gas Turbine Conference and Products Show, New Orleans, Mar. 10 - 13, 1980.

11. A. Adler and B. Hoeks, "Phase-locked Telemetry System for Rotary Instrumentation of Turbomachinery", NASA-CR-159453, Acurex Final Report 78 -284, Sept. 1978.

12. U. Haupt and M. Rautenberg, "Blade Vibration
Measurements on Centrifugal Compressors by Means of Telemetry and Holographic Interferometry", Journal of Engineering for Power, ASME - Paper No. 83-GT-131, Int. Gas Turbine Conference of the ASME, Phoenix/Arizona, 1983.

13. U. Haupt, M. Rautenberg and K. Diefenthäler, "Beschleunigungsfeste 8 Kanal Telemetrieanlage für Schaufelschwingungsmessungen am Radialverdichter", Europäische Konferenz und Fachmesse für Technisches Messen und Telemetrie, Böblingen, Mai 1984.

14. U. Haupt and M. Rautenberg, "Investigations of the Influence of the Non-uniformity of the Flow Downstream a Radial Impeller on the Excitation of Blade Vibration", Fifth International Conference for Mechanical Power Engineering, Cairo, 13 - 15 October, 1984. 